\title{
Patrimônio, documentos e informação
}

\author{
Patrimonio, documentos e información
}

Heritage, documents and information

\author{
Renato CRIVelLi (1), Maria Leandra BIzello (2)
}

Universidade Estadual Paulista, Programa de Pós-Graduação Ciência da Informação, Av. Higyno Muzzi Filho, 737, Cidade Universitária, Marilia, SP, Brasil (1) renatocrivelli@yahoo.com.br (2) mleandra23@gmail.com

\begin{abstract}
Resumen
Este trabajo busca desarrollar una observación sobre el patrimonio histórico monumental, desde la perspectiva de la ciencia de la información, y aún así dibujar una posible conexión entre el contexto de los monumentos del patrimonio y de los documentos centrados en los archivos, con la intención de justificar la inclusión de este último juntos la primera, entre las unidades jurídica y socialmente entendidas como formas de representación de la historia, la memoria colectiva e identidad. Para ello, apoyamos en la literatura en los campos de la antropología, la historia y la arquitectura, para contextualizar los monumentos, y Ciencias de la Información y Archivologia para comprender documento y información, y establecer una proyección [Autores]. ( $\left.{ }^{*}\right)$
\end{abstract}

Palabras clave: Documento. Patrimonio documental. Patrimonio monumental. Información. [Autor]

\section{Patrimônios monumentais nacionais}

O pensamento direcionado ao que hoje entendemos como patrimônios históricos, artísticos, culturais, ecológicos, etnográficos, ou qualquer outra categorização que seja dada, já não pode ser considerado tão recente, mas ainda se mostra como um fenômeno social com muitos pontos e questões abertos à discussão e desenvolvimento. Podemos tomar essa situação pelo simples fato de presenciarmos, atualmente, no cenário cultural brasileiro, uma acalorada discussão sobre a construção da mais nova das categorias patrimoniais, ou seja, os patrimônios imateriais, ou intangíveis. Não se há totalmente definido, até o momento, o que, exatamente, integra essa classe cultural a ser preservada, bem como não se sabe como, exatamente, serão constituídos os meios legais e jurídicos para a preservação e manutenção destes elementos culturais sem apresentação material (1). Mesmo assim, as discussões estão em andamento, com a perspectiva de definir os traços que delimitarão mais um núcleo a se agregar ao conceito, em constante reformulação, de patrimônio.

É tomado como o marco de início dos pensamentos sobre patrimônio, o final do século XVIII,

\begin{abstract}
This work seeks to develop an observation about the monumental historical heritage from the perspective of Information Science, and still draw a possible connection between the context of the monumental heritage and documents, focus on the archival (manuscripts), in the intention of justifying the inclusion of the latter together the first, among the units legally and socially understood as forms of representation of history, collective memory and identity. For this, we support in the literature in the fields of anthropology, history and architecture, to contextualize the monuments, and Information Science and Archival Science to understood documents and information, and set up a projection [Authors]. $\left(^{*}\right)$
\end{abstract}

Keywords: Documents. Documentary heritage. Monumental heritage. Information. [Authors]

durante o período da Revolução Francesa, no qual as estruturas sociais se encontravam num momento de reformulações, o que exigia, automaticamente, a revisão, também, de elementos estruturantes da sociedade, como a identidade, a memória, o passado e a história. Aqueles elementos produzidos pela antiga sociedade, que remetiam diretamente ao contexto monárquico absolutista, deveriam, a princípio, serem destruídos, para que dessem abertura, então, à nova história que se construiria a partir daquele momento. No entanto, essa ação de destruição, levada a efeito, repercutiu de modo oposto, gerando um movimento preservacionista. Como diz Choay (2001, p. 97):

A obra conservadora dos comitês revolucionários resulta de dois processos distintos. O primeiro, cronologicamente, é a transferência dos bens do clero, da Coroa e dos emigrados para a nação. O segundo é a destruição ideológica de que foi objeto uma parte desses bens, a partir de 1792, particularmente sob o Terror e o governo do Comitê de Salvação Pública. Esse processo de destruição suscita uma reação de defesa imediata, comparável à que foi provocada pelo vandalismo dos reformados na Inglaterra. Contudo, na França em revolução, a postura da reação assume outra dimensão e outro significado, político. Ela agora não visa apenas à conservação das igrejas medievais, mas, 
em sua riqueza e diversidade, à totalidade do patrimônio nacional.

Devemos salientar que, com a mudança estrutural ocorrida na França, com a queda do poder monárquico e o início do que chamamos de República, começa, então, a ser trabalhado um novo conceito, que será responsável por reger a sociedade francesa e se proliferar entre as demais sociedades a partir daquele momento, que é o conceito de nação. É tratado em bibliografias internacionais sobre a criação das nações e como elas foram estruturadas e inventadas (Anderson, 2008; Hobsbawn, 1990), no sentido de conduzir ao sentido de um povo, composto de cidadão, unidos através de um sentimento e uma conexão histórica, responsável por determinar, então, o sentido de nacionalidade de cada um e do coletivo. Nesse empreendimento, a utilização de bens, agora transferidos para o poder público (conceito também em consequente fase de desenvolvimento), como forma de afirmação desta nova estrutura de integração social e política, se mostra extremamente útil.

Porém, tais objetos só podem ser utilizados para este fim quando preparados para agir desta forma. Individualmente, uma igreja medieval, é apenas uma igreja medieval. Para aqueles que presenciaram a atividade desta igreja, ainda sob o exercício dos poderes centralizadores, ela será uma lembrança daquele tempo. Para os que não a conheceram naquele momento, e não receberam influências históricas sobre aquele local, será apenas uma igreja medieval. No primeiro destes dois exemplos, a igreja não exercerá uma influência definida como positiva, talvez, no sentido de que a pessoa se recordará de momentos que não lhe eram interessantes, o que pode, inclusive, derivar a reação destrutiva deste objeto. Já no segundo caso, ao sujeito que desconhece qualquer referência sobre aquele objeto, ela não passará de uma igreja medieval (caso isso faça algum sentido ao observador).

Para que tais bens possam ser utilizados pelos poderes em favor da criação da nação, é necessário que, em primeiro lugar, façam com que os indivíduos passem a ser entendidos enquanto coletividade, ou seja, devem servir como um instrumento integrador. Caso contrário, eles não efetivarão o que foi intencionado.

Então, para que isso ocorra, o objeto não deve, em princípio, ser deixado ao trabalho indiscriminado da própria população, ainda menos em tempos de reestruturação social. A proposta deve ser conduzida através do investimento de valores específicos a estes objetos, para que, então transfigurados, passem alguma mensa- gem aos seus observadores. O objetivo é que este objeto exerça influência sobre a população à qual se relaciona. Choay (2001) nos fala em valores nacionais, valores cognitivos, valores econômicos e valores artísticos, sendo que todos se congregam, de alguma maneira, a fim de sustentar um ideal delineado em consonância com os interesses do poder instituído (op.cit., p. 119):

Fazendo dos monumentos históricos propriedade, por herança, de todo o povo, os comitês revolucionários dotavam-nos de um valor nacional que lhes atribuíam novos usos, educativos, científicos e práticos.

Ou seja, podemos entender que esses objetos, sobreviventes de épocas anteriores, quando ingressos à sociedade atual, para que sejam entendidos enquanto um instrumento condutor do interesse superior, de modo a afetar a conduta da massa, devem ser investidos de um valor nacional, uma recontextualização, no qual seus usos e qualificações anteriores não são, necessariamente, eliminados, mas revestidos de um novo entendimento, uma nova interpretação a ser realizada.

Fonseca (1997, p. 36-37) diz que esses valores investidos aos bens para que sejam, então, entendidos como patrimônios nacionais, são, na verdade:

[...] um discurso de segundo grau: às funções e significados de determinados bens é acrescentado um valor específico enquanto patrimônio, o que acarreta a ressemantização do bem e leva a alterações no seu sistema de valores. [grifo nosso]

Destacamos nesta citação a palavra ressemantização, um neologismo interessante utilizado pela autora no intuito de dizer que o bem que entendemos como patrimônio, na verdade, somente o é por que passa por um processo de reconstrução semântica, estruturada especificamente para a atuação, ou representação, junto à sociedade diretamente relacionada.

José Reginaldo Gonçalves (1996) trabalha essa questão aos olhos da antropologia, que nos mostra, então, uma consideração bastante interessante sobre o investimento dos valores aos patrimônios.

Este autor entende que os patrimônios são criados e sustentados, assim como qualquer outro símbolo nacional e seguindo seu mesmo caminho, através do que ele chama de Narrativas Nacionais, ou seja, "[...] modalidades discursivas cujo propósito é a construção de uma 'memória' e de uma 'identidade' nacionais", e entende que estes dois elementos são utilizados, de acordo com a classe de intelectuais dedicados às questões do patrimônio nacional, "[...] em 
função do empreendimento de construção da 'nação'." (1996, p. 11).

O que podemos compreender, portanto, após este levantamento, é que os patrimônios, desde sua idealização e criação, têm por função primordial, contribuir na construção do conceito de nação e do sentimento nacional, com atuação direta na sociedade, agindo dentro do contexto social, ou seja, entre os cidadãos, dentro das cidades, em parques, praças, prédios de governos e demais instituições públicas, etc., trazendo à tona elementos como memória e identidade coletivas, investidas e destacadas através de um discurso, ou uma narrativa, elaborada por uma classe dominante na sociedade e com autoridade para determinar o que é, ou não, patrimônio, logo, o que representa, ou não, o passado, a memória, a identidade daquele grupo, ou seja, determinam a representação do grupo em si.

\section{Documento e Informação}

A proposta deste tópico é rever alguns elementos que conectam e orbitam os entendimentos feitos por parte da Ciência da Informação (Cl) acerca dos documentos e da informação, ambos constantes do seu cerne epistemológico.

Por se tratarem de objetos com vasta abrangência conceitual, será necessário que nos dois casos, seja no documento, seja na informação, estipulemos recortes específicos de estudo, a fim de não dispersar o foco deste trabalho. Esse recorte se desenhará ao longo do desenvolvimento deste tópico.

Para darmos início à discussão, buscaremos contextualizar uma visão sobre o documento, palavra utilizada de forma tão rotineira e vulgar por qualquer área de conhecimento e também pelo senso comum. Para a visão da $\mathrm{Cl}$, tomamos como base os estudos realizados por Paul Otlet (1937) acerca da contextualização e conceitualização do documento, e sua diferenciação de Documentação.

Para este autor (ibidem, 1937):

Documento é o livro, a revista, o jornal; é a peça de arquivo, a estampa, a fotografia, a medalha, a música, é também, atualmente, o filme, o disco e toda a parte documental que precede sou sucede a emissão radiofônica.

Destaque seja dado para a amplitude do conceito que Otlet apresenta em seu entendimento de documento, e consideremos, ainda, a data de sua produção, 1937, numa adequação especulativa para os tempos atuais, possivelmente o autor acrescentaria muitas coisas à categoria de documento, tais como discos digitais, cartões de memória, e mesmo páginas e repositórios virtuais.

Nos permitimos tal especulação não com base nos exemplos descritos na citação apresentada, mas antes, com os pensamentos apresentados por Otlet quanto a elementos que constituirão um objeto que poderá ser chamado de documento, o que, então, nos permite trabalhar sobre suposições dessa ordem. $\mathrm{O}$ autor diz que sobre três ordens de elementos constituintes de todo documento que devem ser consideradas, e que são os elementos materiais, entendidos enquanto a substância do documento, sua forma e seu acabamento, ou seja, a apresentação física do objeto; os elementos gráficos, que incluem textos, imagens reais ou convencionais, notações, o que podemos entender enquanto aqueles elementos que permitirão ao documento ser inteligível ao que o observar; e por último, os elementos intelectuais, que o autor descreve da seguinte forma:

Os elementos intelectuais são os mais importantes; mas sua possibilidade de expressão está, porém, em função dos dois primeiros. Trata-se, sempre, de dar forma a qualquer fragmento retirado da realidade, de exprimi-la tal qual é, ou de maneira tal que a imaginação possa representá-la. Para esse fim escolhe-se (elimina-se, retém-se, deforma-se, amplifica-se, diminui-se, exagera-se ou atenua-se) e agrupa-se em certa ordem. A escolha e o agrupamento são determinados pelos fins, que podem ser: ou registrar objetivamente o que é, ou o de fazer compreender por certa categoria dada do espírito, ou o de persuadir a fim de obter tal adesão ou tal ato voluntário, ou, ainda, o de distrair, divertir, exaltar, encorajar, consolar.

Entende-se com isso, em primeiro lugar, que o documento necessita, obrigatoriamente, de uma apresentação material e gráfica para que possa, então, ser considerado dele os elementos intelectuais, entendidos, em suma, como aquilo que efetivamente dará o sentido ao documento, ou, aquilo que contextualizará o documento em sua função de ser. Em segundo lugar, é deixado claro nesta explicação do autor que estes elementos intelectuais do documento são, normalmente, elementos construídos socialmente, seja pelo indivíduo específico, seja pela coletividade social, por serem eles, os documentos, entendidos como elementos extraídos da realidade, com o objetivo de representá-la de algum modo que possa ser apreendido pela mente; para que essa representação seja efetivada, são aplicadas as formas de organização, entendidas por Otlet como as tarefas de escolher e agrupar em certa ordem, sendo estas ditadas, exclusivamente, por algum interesse específico daquele que o faz. 
Briet (1951, apud Buckland, 1991), entende documento enquanto "qualquer indicação concreta ou simbólica, preservada ou registrada, para reconstruir ou provar um fenômeno, seja físico ou mental." (2). A autora francesa ainda defende a ideia de que um documento é entendido enquanto tal a partir do momento em que passa por um processo de propósito informacional, ou seja, qualquer coisa pode ser um documento quando configurado, socialmente, como um veículo de informação (3).

Com isso, podemos entender a necessidade, seja no pensamento de Otlet, seja no de Briet, do valor informacional para que o documento seja visto como tal, o que coloca, então, a informação presente como um elemento com maior força determinante em relação ao formato e ao suporte.

Definir informação é uma tarefa árdua e complexa, até mesmo para a $\mathrm{Cl}$, que detém bem mais de uma teoria sobre o entendimento de informação e como tratá-la, de modo a cumprir com a proposta epistêmica e prática da área (4). Buckland (1991) nos demonstra três usos para a palavra informação, sendo eles, "Informaçãocomo-Processo", "Informação-como-Conhecimento" e "Informação-como-coisa", e que podem ser assim interpretados, o primeiro, a informação enquanto o ato de informar alguém sobre algo que mudará seu conhecimento, ato de contar; o segundo caso pode ser entendido enquanto aquilo que é apreendido da informação-como-processo, ou seja, exatamente aquilo que é comunicado ao outro e que causará algum efeito em seu conhecimento (5); já o último caso, informação-como-coisa, diz respeito à indicação de objetos com potencial informativo como sendo eles, por si só, a informação.

Nesse sentido, o autor destaca a relação existente entre estes três casos de aplicação da palavra informação a partir da compreensão de que aquilo que é expresso por uma pessoa, ou grupo de pessoas, é sempre imaterial e não tem condições de ser tocado ou mensurado (informação-como-conhecimento). Para que seja, então passado para outra pessoa, ou grupo de pessoas, (informação-como-processo) esse pensamento deve ser representado de forma física; algo material, como um texto ou um sinal, deve ser utilizado (informação-como-coisa). Nesse momento, identificamos de forma bastante clara a ligação intrínseca entre o documento e a informação, ao ponto que o documento é a organização materializada de uma informação que, por algum motivo ou interesse específico, foi representada e expressa ou, ao menos, intencionada ser (6).
De fato, com essa visão apresentada até o momento, podemos compreender que qualquer coisa é, em potencial, um documento. A $\mathrm{Cl}$ tem como foco de suas atividades a informação registrada, ou seja, a informação preservada em algum suporte durável, seja ele papel, pedra, plástico, CD ou um servidor virtual, e devemos levar em conta, ainda, os três instrumentos sociais utilizados para a gestão dessas informações, que são as bibliotecas, os arquivos e os museus. Todos, cada um segundo a sua especificidade, são instituições de guarda e gestão de informações registradas com objetivos claros de acumulação, organização e disseminação deste material. As bibliotecas dedicadas a coleções de publicações literárias e científicas; os arquivos incumbidos dos fundos de arquivos de pessoas físicas ou de gestões administrativas públicas ou privadas; os museus responsáveis pelo colecionamento de peças tridimensionais oriundas de tempos históricos da cultura humana, da história natural ou qualquer outra temática organizada.

Se pensarmos de acordo com o senso comum, as bibliotecas detêm livros, os museus, objetos, enquanto os arquivos, documentos. Vemos o uso do termo documento reduzido a uma única representação informacional, por ser esta a forma organizada mais comum e presente no dia-a-dia da sociedade. Não é um equívoco pensar nos documentos de arquivo enquanto documentos, pois estes realmente o são. Mas o são de forma condizente com os sentidos de documentos apresentados anteriormente, enquanto uma forma organizada para representar um fenômeno social que, por algum motivo ou interesse específico, pretende ser comunicado, ou informado, por uma entidade à outra entidade. Entendamos deste modo: os documentos de arquivo são produzidos, primordialmente, na condição de instrumentos burocráticos a fim de efetivar, de forma registrada, atividades e tarefas da gestão administrativa pública ou privada, bem como de pessoas físicas, ou seja, existe a atividade que deve ser realizada, e existe o documento de arquivo, que se apresenta como uma representação materializada dessa atividade, investida de valores informativos específicos que the conferem autoridade jurídica testemunhal e probatória.

Um diferencial desta classe de documentos se encontra na transfiguração que ocorre junto ao seu valor informativo, ou em seu elemento intelectual, nas palavras de Otlet. Estes documentos de arquivo já são criados com função de informar, mas com um objetivo específico, que é o de levar a efeito uma atividade, tarefa ou interesse por parte daquele que o produziu. Após 
cumprir esta obrigação, seu valor é alterado, e passa a servir como fonte informativa histórica, enquanto a representação registrada daquela tarefa realizada em outro tempo. Há, neste caso, uma reestruturação do valor funcional do documento de arquivo, de administrativo para histórico, sendo que a informação continua a mesma, e a interpretação caberá àquele que dela fizer uso (Schellenberg, 2006; Bellotto, 2004; Rousseau, Couture, 1998; Cruz Mundet, 1996).

Em se tratando dos documentos públicos oficiais que já são considerados históricos e habitam os arquivos públicos de suas instâncias de poder produtoras, esse novo valor funcional que recebem os colocam na condição de instrumentos de preservação da informação histórica nacional. Com potencial informativo intrínseco, a representação da realidade que o gerou é facilmente extraída, o que confere a este documento um potencial de ação instrumental que permite garantir a criação, sustentação e manutenção da memória histórica e da histórica social.

\section{Considerações}

Estabelecemos no começo deste trabalho a contextualização que levou à criação do conceito de patrimônio nacional enquanto um fenômeno social desenvolvido de modo a exercer o papel de instrumento integrador no objetivo de construção da nação e do sentimento de nacionalidade, sendo que, para tal empreendimento, eles são reorganizados e ressemantizados através de um discurso especificamente desenvolvido, que será responsável por elevá-lo à categoria de patrimônio.

Remontamos também uma linha de pensamento a fim de compreender e contextualizar o documento dentro das especificidades da $\mathrm{Cl}$, em conjunto com os conceitos de informação. Identificamos como o elemento responsável por conferir a competência de documento é o valor informativo, que já o acompanhe desde sua gênese, ou que the seja investido de modo intencional após um processo de propósitos informacionais. Todo este contexto coloca o documento na condição de representação de algo, algum fenômeno.

Após estabelecermos estes dois parâmetros contextuais paralelos, podemos perceber que há uma relação potencial entre os patrimônios nacionais de serem inseridos na qualidade de documento, após ser aquele objeto do cotidiano, podendo ser até mesmo uma igreja medieval, como exemplificamos no início, trabalhado de modo a se reconfigurar em significados e adquirir um novo valor semântico, apoiado em uma narrativa histórica consistente e bem definida, que não deixará margens para ser questionado, a não ser em momentos de crise estrutural da sociedade.

No mesmo sentido, os documentos de arquivo sustentam o mesmo potencial, com o diferencial de que já nascem com um valor informativo, que é funcionalmente alterado após ingressar ao arquivo histórico. No entanto, no Brasil, os documentos de arquivos históricos são vistos como marginais perante os monumentos e monumentos históricos, artísticos, ecológicos e demais categorias patrimoniais, ocasionando a desvalorização dos documentos de arquivo enquanto patrimônios, ou seja, elementos sociais responsáveis por sustentar a memória e a identidade sociais.

As ideias trazidas por Buckland, de interpretar a informação como uma "coisa", e de ser essa "coisa" que dá o sustento para a informação ser disseminada, aliada aos pensamentos de Paul Otlet e Suzanne Briet, respectivamente, acerca do elemento intelectual como o responsável por dar forma a um elemento retirado da realidade, selecionado e organizado de modo a transmitir alguma informação e de que qualquer coisa pode vir a se tornar um documento, importando ter um valor informacional investido por um propósito informacional, acreditamos servir como uma ponte conceitual para unificar estes dois universos complementares, arquivos e patrimônios, mas que ainda necessitam de uma aproximação mais consistente, podendo gerar, ainda o sustento desta classe patrimonial marginalizada no Brasil, referente aos patrimônios documentais.

Essa ponte pensada terá a função de aproximar estes dois universos, utilizando por modo de aproximação a adaptação dos conceitos de documento e dos entendimentos sobre a transformação de algum objeto em documento a partir do momento que este objeto absorve uma função informativa que não detinha antes. Nesse sentido, os patrimônios arquitetônicos, monumentais, artísticos, ou qualquer outra categoria de patrimônios, somente será entendido enquanto tal após sua transformação em documento, pois, sem esse valor informativo investido a eles, através do trabalho histórico-social de construção discursiva, seriam apenas objetos de uso/consumo, assim como qualquer outro. Com esta proposta de conexão, espera-se que os documentos de arquivo se mostrem em pé de igualdade em relação aos monumentos e demais patrimônios, que concentram todos os olhares dos poderes públicos, dos investidores, bem como da comunidade local e da estrangeira. 


\section{Notas}

(1) Importante esclarecer que, em se tratando dos chamados patrimônios imateriais, elencam-se como integrantes, por exemplo, danças, rituais e demais tradições que não sustentam uma apresentação materializada, como uma imagem de santo ou uma bandeira. A ausência de apresentação material deve ser entendida, no caso de uma dança, como a intenção da dança, e não, no sujeito que dança.

(2) Any concrete or symbolic indication, preserver or recorded, for reconstructing or for proving a phenomenon, whether physical or mental." (Tradução nossa).

(3) Nesse sentido, existe o clássico exemplo dado pela própria autora, onde diz de um animal selvagem, quando na natureza, não apresenta qualificação para ser visto como um documento. A partir do momento que este animal é capturado e posto em exibição em um zoológico, ou ainda utilizado para experimentos e estudos de qualquer ordem, ele é recontextualizado, e sua função passa a agregar, também, um valor documental.

(4) Para uma visão geral sobre as teorias da Ciência da Informação (Araujo, 2009).

(5) Seja esse efeito esclarecedor, ou perturbador. O autor salienta o potencial de incerteza da informação-comoconhecimento.

(6) "Knowledge, however, can be represented, just as an event can be filmed. However, the representation is no more knowledge than the film is the event. Any such representation is necessarily in tangible form (sign, signal, data, text, film, etc.) and so representation of knowledge (and of events) are necessarily 'information-as-thing'." (Buckland, 1991)

\section{Referencias}

Anderson, Benedict (2008). Comunidades Imaginadas. São Paulo: Cia das Letras.

Araujo, Carlos Alberto Ávila (2009). Correntes teóricas da Ciência da Informação. // Ciência da Informação. Brasília, DF. 38:3 (set./dez.) 192-204
Bellotto, H. L. (2004). Arquivos permanentes: tratamento documental. Rio de Janeiro: FGV.

Buckland, Michael. K. (1991). Information as thing. // Journal of the American Society for Information Science. 42:5, 351-360.

http://people.ischool.berkeley.edu/ buckland/thing.html (17 ago. 2009)

Choay, Françoise (2001). A alegoria do patrimônio. São Paulo: Ed. Unesp,

Cruz Mundet, José Ramón (1996). Los conceptos de archivo y documento. In: Cruz Mundet, José Ramón. Manual de Archivistica. Madrid: Fundación Sãnchez Ruipérez, Pirámide.

Fonseca, Maria Cecília Londres (1997). O patrimônio em processo: trajetória da política federal de preservação no Brasil. Rio de Janeiro: Ed. UFRJ/MinC - IPHAN.

Gonçalves, José Reginaldo Santos (1996). A retórica da perda: os discursos do patrimônio cultural no Brasil. Rio de Janeiro: Ed. UFRJ/MinC - IPHAN

Hobsbawm, Eric J. (1990). Nações e nacionalismo desde 1780: programa, mito e realidade. Rio de Janeiro: Paz e Terra.

Otlet, Paul (1937). Documentos e documentação. // Congresso de documentação universal, Paris. Discursos... Rio de Janeiro: Imprensa Nacional, 1947. Separata. http://www.conexaorio.com/biti/otlet. 01/05/2012).

Rousseau, Jean Yves, Couture, Carol (1998). Os fundamentos da disciplina arquivística. Lisboa: Publicações Dom Quixote.

Schellenberg, Theodore R. (2006). Arquivos modernos: princípios e técnicas. Rio de Janeiro: FGV.

Enviado: 2012-05-17. Versión corregida: 2012-08-21. Aceptado: 2012-08-21.

(*) Nota del editor: Excepcionalmente, se mantuvieron los resúmenes y palabras clave propuestas por los autores a petición de María Leandra Blzello. / Editor's note: Exceptionally, original authors' abstracts and keywords were included, accepting the petition of Maria Leandra Bizello (2012-09-21) 